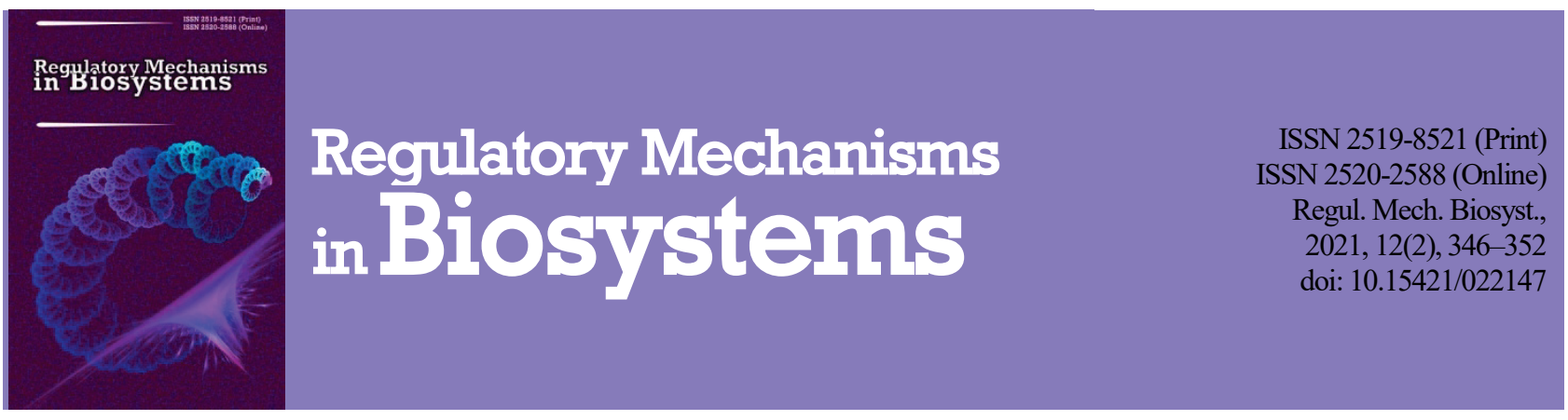

\title{
Effect of Cameraria ohridella feeding on Aesculus hippocastanum photosynthesis
}

\author{
K. K. Holoborodko, O. V. Seliutina, I. A. Ivanko, A. A. Alexeyeva, M. V. Shulman, O. Y. Pakhomov \\ Oles Honchar Dnipro National University, Dnipro, Ukraine
}

Article info

Received 12.04.2021

Received in revised form 10.05.2021

Accepted 11.05.2021

Oles Honchar Dnipro National University,

Gagarin av., 72,

Dipro, 49010, Ukraine

Tel.: + 38-066-795-63-20.

E-mail:

goloborodko@ua.fm

\author{
Holoborodko, K. K., Seliutina, O. V., Ivanko, I. A., Alexeyeva, A. A., Shulman, M. V., \& Pakhomov, O. Y. (2021). Effect of Cameraria \\ ohridella feeding on Aesculus hippocastanum photosynthesis. Regulatory Mechanisms in Biosystems, 12(2), $346-352$. \\ doi:10.15421/022147
}

The complex of invasive species of phytophagous insects that can adapt to novel living conditions is constantly increasing. The ecological effect of their vital activity in the new environment is almost impossible to predict. As a result, invasions undesirable in the economic sense are often observed. The horse -chestnut leaf miner (Cameraria ohridella Deschka \& Dimič, 1986, Gracillariidae) is one of these problematic invader species in the introduced range of the horse chestnut (Aesculus hippocastanum (Linnaeus, 1753), Sapindaceae). We studied the effect of $C$. ohridella on the state of the photosynthetic apparatus in Ae. hippocastanum leaves. Photosynthesis is the one of the processes most vulnerable to stress factors, so information about the state of photosynthetic apparatus in a plant under the influence of phytophage feeding obtained with fluorescence analysis can be significant. The feeding effect of $C$. ohridella caterpillars on the functional state and activity of Ae. hippocastanum photosynthetic apparatus was studied. We studied critical parameters of chlorophyll fluorescence induction reflecting the effect of a single C. ohridella generation (feeding the caterpillar for the five stages of this species' development) on the functional links of the photosystem II in Ae. hippocastanum leaves. The data obtained show a decrease in PS II quantum efficiency (inhibition of photosynthetic activity) in the leaves from different parts of the crown; it suggests the destructive effect of $C$. ohridella caterpillar feeding on Ae. hippocastanum photosynthetic apparatus. Values of all key parameters of chlorophyll fluorescence indication evidence inhibition of photophysical and photochemical processes of photosynthesis and impaired coherence of Calvin cycle reactions. Study of the feeding effect of $C$. ohridella caterpillars on the efficiency of the main enzyme in the Calvin cycle (which closely correlates with the coefficient of fluorescence induction that characterizes the efficiency of dark photosynthetic processes) showed a significant decrease in its activity in the leaves of both the illuminated and shaded parts of the crown. Our study has shown that the method of chlorophyll fluorescence induction allows one to determine the general state of a plant in an express regime by evaluating the main process of plant life as photosynthesis. Analysis of chlorophyll fluorescence parameters is a powerful and effective tool for determining the effect of phytophages on the plant body. The obtained data allow us to apply the method of analyzing chlorophyll fluorescence induction in practice to establish the physiological state of tree flora in forests and garden farms.

Keywords: invasive species; lepidopteran miners; plant ontogenesis; chlorophyll; chlorophyll fluorescence; plant photosynthetic apparatus.

\section{Introduction}

According to estimates of the Invasive Species Specialist Group (ISSG) of the World Conservation Union (IUCN) and the European Plant Protection Organization (EPPO), the number of species that have entered into novel, untypical environments under the influence of direct or indirect human action is annually increasing (Lopez-Vaamonde et al., 2010). Having adapted, some of these live organisms begin to compete with native species, interfering with the established ecological functions of various ecosystems (Brygadyrenko \& Nazimov, 2015). Such invasions can often bring irreparable environmental consequences that cause significant biological disturbances in the function of entire ecosystems resulting in significant economic losses to various economic sectors (Kirichenko et al., 2019). Currently, a list of 435 species enumerates quarantine organisms (Holoborodko et al., 2016) having different hazard statuses, both environmental and economic, because their life activities annually cause direct economic losses. The range of potential invasive species that can enter the territory of Ukraine is currently estimated at 1,500 (Holoborodko et al., 2016). Disturbances in the natural functioning of ecosystems caused by the effect of invasive species can cause both direct and indirect risks directly to human health (Inghilesi et al., 2013; Voronkova et al., 2018).

The horse-chestnut leaf miner (Cameraria ohridella Deschka \& Dimič, 1986) is an invasive phytophage from the family of leaf blotch miner moths (Gracillariidae Stainton, 1854) which completely settled the territory of Ukraine at the beginning of the XXI century (Akimov et al., 2003). C. ohridella is trophically associated with the horse chestnut (Aesculus hippocastanum (Linnaeus, 1753)). By its vital activity, this invasive species threatens the existence of Ae. hippocastanum, inhabiting its trees sometimes at $95 \%$. Taking into account that the horse chestnut is one of the main tree species in populated areas of Ukraine, invasion by this insect species is of increased interest. Our results demonstrate activation of the enzymatic antioxidant defense system of Ae. hippocastanum in response to the damaging effect of the horse-chestnut leaf miner, which allows the plant to survive and complete the ontogenesis program in unfavourable conditions. The most significant factor in protecting cells from caterpillar activity involves an increase in the activity of guaiacol peroxidase, which indicates an increase in the cell barrier properties (Shupranova et al., 2019).

On the other hand, the effect of $C$. ohridella on the processes of Ae. hippocastanum photosynthesis remains unclear. Photosynthesis is one of the processes most vulnerable to stress factors, so significant information about the state of the photosynthetic apparatus in a plant under the influence of various abiotic and biotic factors can be obtained using fluorescence analysis (Huang et al., 2012; Kargar et al., 2019; Pérez-Bueno et al., 2019). Chlorophyll fluorescence is an indicator that allows us to study the passage of photochemical reactions in living objects associated with the operation of photosystem II (FSII), the most sensitive to environmental factors. The results of studies on chlorophyll fluorescence intensity contribute to a deeper understanding of the regulatory mechanisms 
that ensure efficient energy conversion in the primary and subsequent stages of photosynthesis (Kalaji et al., 2017; Chen et al., 2019; da Silva et al., 2020). Our study aimed to establish the features of the influence of vital activity $C$. ohridella on the process of Ae. hippocastanum photosynthesis using the chlorophyll fluorescence induction estimation method.

\section{Material and methods}

The study was conducted during the 2019 growing season in Dnipro city (Ukrainian North Steppe subzone) (Brygadyrenko, 2015, 2016; Faly et al., 2017). The city is located in the zone of temperate latitudes with a fairly active atmospheric circulation (the predominant movement of air masses from East to West). The territory has a temperate-continental climate. Significant fluctuation in weather conditions from year to year is one of the features of the climate in the territory. Moderately wet years alternate with sharply dry years, and hot dry winds are not uncommon. In general, the climate is characterized by rather cool winters and hot summers. In 1931, the Botanical Garden at Oles Honchar Dnipro National University $\left(48.430957^{\circ} \mathrm{N}, 35.040264^{\circ} \mathrm{E}, 127 \mathrm{~m}\right.$ above sea level) was founded on the territory of Dnipro city. A test site was laid on its territory, with horse chestnut (Ae. hippocastanum) trees having similar morphological and tax features (trunk diameter 132-151 cm; height $17-21 \mathrm{~m}$ ). In general, the edaphotope of the selected test site is represented by degraded ordinary low-humus chernozem $(1.0-4.0 \%)$.

To study the feeding effect of caterpillars of $C$. ohridella on photosynthesis processes in Ae. hippocastanum selected leaves of medium forma- tion, we sampled five leaves on the illuminated and shaded sides from annual vegetative growth in the lower third of the crown of different exposures in dry weather. Each examined leaf was marked separately. The study was conducted from 17.05.2019 to 13.06.2019, which corresponded to the full development cycle (5-age caterpillars) of the secondgeneration $C$. ohridella. Thus, the study elucidated the influence of each age of the second-generation caterpillar. The age of the caterpillar was determined by the visual parameters of the mine. The damage degree to the leaf blades of the horse chestnut by $C$. ohridella was evaluated visually with a scale previously developed by us (Shupranova et al., 2019).

Light intensity measurements were made with RCE-174 luxmeter (PCE Instruments, Germany, 2018). Temperature and relative humidity measurements were made with HE-173 thermohygrometer (Huato Electronic Co. LTD, China, 2018). A portable fluorometer "Floratest" was used for the diagnosis of photosynthetic disorders of native chlorophyll in living Ae. hippocastanum leaves. The portable fluorometer "Floratest" comprises a base unit with a graphic liquid crystal display, control buttons, a remote optoelectronic sensor, connecting cable to the USB port of a personal computer, and a network adapter (Fig. 1). The remote optoelectronic sensor includes an LED that has a maximum radiation intensity of $\lambda=470 \pm 20 \mathrm{~nm}$. Irradiation indicators in the sensor were the following: irradiation wavelength $470 \pm 15 \mathrm{~nm}$; irradiated spot area not less than $15 \mathrm{~mm}^{2}$; illumination within the spot at least $2.4 \mathrm{~W} / \mathrm{m}^{2}$. Signal reception indicators in an optoelectronic sensor: the spectral range of fluorescence intensity measurement was $670-800 \mathrm{~nm}$; receiving window area $9 \mathrm{~mm}^{2}$; photodetector sensitivity at $\lambda=650 \mathrm{Nm}$ was $0.45 \mathrm{~A} / \mathrm{W}$.

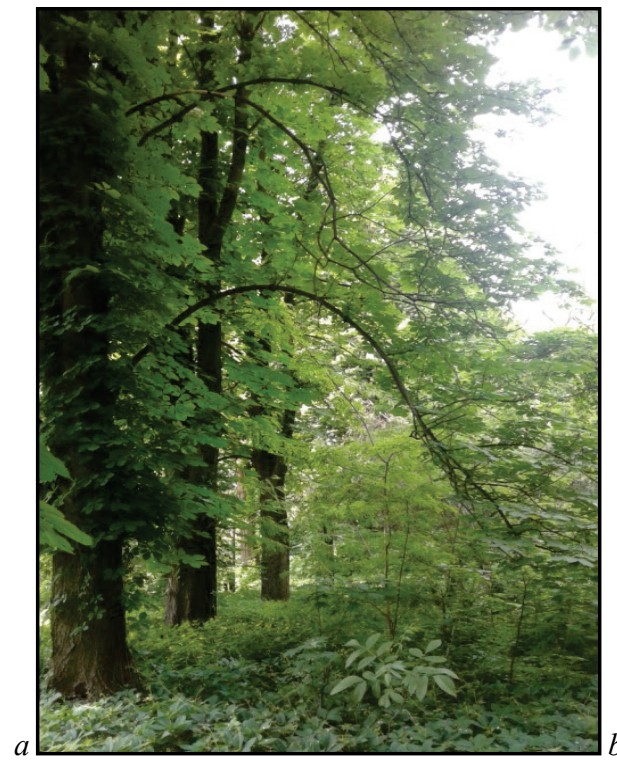

Fig. 1. Experimental Aesculus hippocastanum trees ( $a$ ) and portable fluorometer "Floratest" (b)

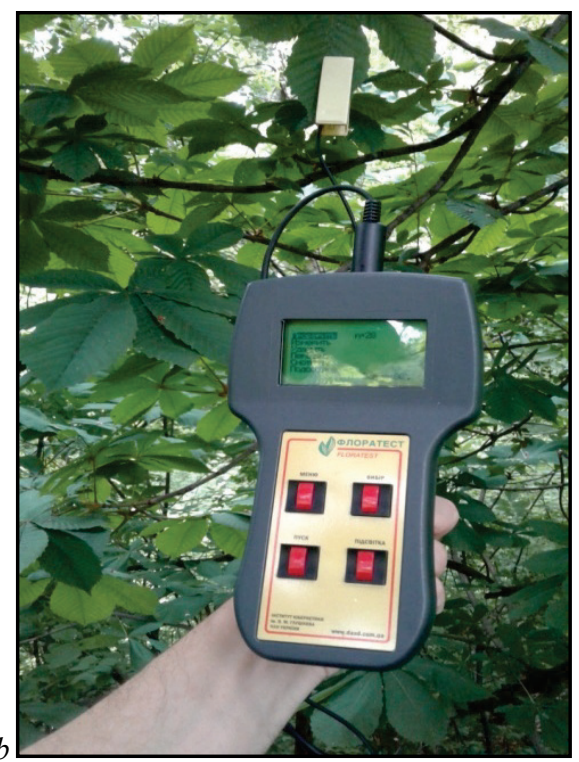

A light filter at the input of the photodiode amplifier was used to study the intensity of chlorophyll fluorescence that occurs in the red region of the spectrum. In the optoelectronic head (clip), LEDs are mounted, the light from which is directed to one point of the leaf under study, and one photodetector. It is provided that the radiation intensity of light diodes and the sensitivity of the photodetector of the sensor head can be changed during the measurement process.

The internal memory capacity of the device provides long-term storage of information about 40 chlorophyll fluorescence induction curves.

Observations were made on live Ae. hippocastanum leaves. After the start of light exposure, the intensity of chlorophyll fluorescence (fluorescence induction or fluorescence induced by light) begins to change significantly over time. The time dependence of the chlorophyll fluorescence intensity has the characteristic form of a curve with one or more maximum and is called the chlorophyll fluorescence induction curve (Kautsky curve, Fig. 2). The shape of this curve is quite sensitive to changes that occur in the photosynthetic apparatus in plants when adapting to different environmental conditions, which has become the basis for the widespread use of the Kautsky effect in the study of photosynthesis. At the initial time point, all channels of photosynthetic electron transfer are open and the maximum energy of excited electrons goes to the photosynthetic process. During this period, chlorophyll fluorescence is minimal and its intensity on the Kautsky curve is denoted by $F_{0}$. The transition from $F_{0}$ to $F_{p}$ is caused by the transfer of electrons from the reaction centers of FS II via pheophytin to the primary acceptors (chions). The transition from $F_{0}$ to $F_{p}$ is observed, for example, with a short period of dark adaptation. The entire segment from $F_{0}$ to $F_{m}$ is called the fast fluorescence phase or variable fluorescence. The slow phase of chlorophyll fluorescence induction represents all induction transitions after reaching the peak value by $F_{m}$ (Gorbunov \& Falkowski, 2021). It is known that certain segments of the chlorophyll fluorescence induction curve are indicators of the corresponding physiological processes in the photosynthetic chain (Table 1). Therefore, violations of individual links of photosynthesis caused by exo- and endogenous factors are manifested in characteristic changes in the corresponding segments of the chlorophyll fluorescence induction curve.

Features of chlorophyll fluorescence induction depend on the state of the entire photosynthetic system and reflect the kinetics of the flow of all links in the biochemical chain of photosynthesis (Govindjee, 2004). Changes in any part of photosynthesis cause a change in the appearance of the chlorophyll fluorescence induction curve. Therefore, based on the 
appearance of this curve, it is possible to diagnose the current state of the photosynthetic apparatus in the plant, evaluate changes in the photosynthesis efficiency with changes in the light regime, temperature, humidity, and other factors.

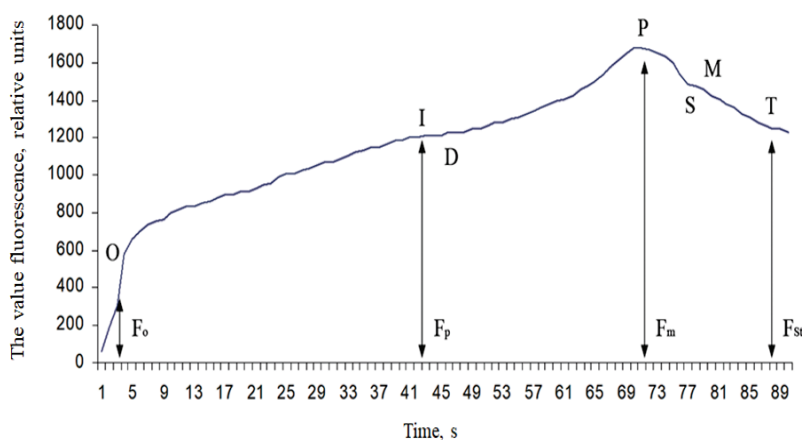

Fig. 2. Typical chlorophyll fluorescence induction curve (Kautsky \& Hirsch, 1931): $F_{0}$ is the initial value of fluorescence induction after irradiation is turned on; $F_{p}$ is the "plateau" fluorescence induction value; $F_{m}$ is the maximum value of fluorescence induction;

$\mathrm{F}_{\mathrm{St}}$ is the stationary value of fluorescence induction after light adaptation of a plant leaf

Table 1

Characteristic segments of the chlorophyll fluorescence induction curve and their diagnostic significance

\begin{tabular}{cccc}
\hline $\begin{array}{c}\text { The CFI } \\
\text { segment }\end{array}$ & $\begin{array}{c}\text { Type } \\
\text { of the segment }\end{array}$ & $\begin{array}{c}\text { Possible } \\
\text { time } \\
\text { interval, } \mathrm{s}\end{array}$ & $\begin{array}{c}\text { Stages of the photosynthetic process that } \\
\text { this segment provides information about }\end{array}$ \\
\hline Point $\mathrm{O}$ & initial segment & $0-5$ & $\begin{array}{c}\text { efficiency of chlorophyll II light } \\
\text { collection and reaction centers }\end{array}$ \\
\hline $\mathrm{O}-\mathrm{I}-$ & $\begin{array}{c}\text { exit to the main } \\
\text { maximum }\end{array}$ & $\begin{array}{c}0.1-10.0 \\
(0.1-1.0)\end{array}$ & $\begin{array}{c}\text { the electron transport link (from } \mathrm{H}_{2} \mathrm{O} \text { to } \\
\mathrm{PD} \text { (ferrodoxin) and NADP) is the so- } \\
\text { called "Light Stage" of photosynthesis }\end{array}$ \\
$\mathrm{D}-\mathrm{P}-\mathrm{S}-\mathrm{M}$ & $\begin{array}{c}\text { descending and } \\
\text { moving to the } \\
\text { second maximum }\end{array}$ & $\begin{array}{c}3.0-50.0 \\
(0.5-10.0)\end{array}$ & $\begin{array}{c}\text { activation (via PD) of the Calvin cycle } \\
\text { enzyme proteins, establishment of the } \\
\text { pH gradient in membranes, reduction } \\
\text { of competing acceptors }\left(\mathrm{O}_{2}, \mathrm{NO}_{2} \text {, etc.) }\right.\end{array}$ \\
\hline $\mathrm{M}-\mathrm{T}$ & $\begin{array}{c}\text { descending and } \\
\text { entering stationary } \\
\text { mode }\end{array}$ & $\begin{array}{c}10-2000 \\
(10-300)\end{array}$ & $\begin{array}{c}\text { adjustment of reactions in the Calvin } \\
\text { cycle and flows of substances through } \\
\text { membranes and through leaf vessels. }\end{array}$ \\
\hline
\end{tabular}

\section{Results}

The microclimatic parameters in which the experimental tree is located affect the vital activity of all ages of $C$. ohridella caterpillars (Fig. 3). The temperature regime and humidity regime significantly affect the features of induction changes in chlorophyll fluorescence that occur under the influence of $C$. ohridella caterpillar feeding. The difference in such impact is significant both for different generations of $C$. ohridella and for different positions of experimental leaves in the crown (shaded-illuminated parts). There was no significant effect of leaf lighting conditions on caterpillar feeding (Fig. 3b).

During the caterpillar development (5 stages), there is a gradual decrease in the values of all the main indicators $\left(\mathrm{F}_{\mathrm{o}}, \mathrm{F}_{\mathrm{m}}, \mathrm{F}_{\mathrm{p}}\right.$, and $\left.\mathrm{F}_{\mathrm{St}}\right)$ of the chlorophyll fluorescence induction curve (Kautsky curve, Fig. 4) of damaged Ae. hippocastanum leaves. A significant difference in the influence of different caterpillar ages and leaf crown position was established for all the main indicators of the chlorophyll fluorescence induction curve. The only exception is the initial value of fluorescence induction $\left(\mathrm{F}_{\mathrm{o}}\right)$, for which no such dependence has been established (Fig. 4a).

The calculated parameters as variable chlorophyll fluorescence $\left(\mathrm{F}_{\mathrm{v}}=\right.$ $\left.\mathrm{F}_{\mathrm{m}}-\mathrm{F}_{0}\right)$ and the maximum efficiency of primary photosynthesis processes $\left(\mathrm{E}_{\mathrm{f}}=\mathrm{F}_{\mathrm{v}} / \mathrm{F}_{\mathrm{m}}\right)$ reliably depend on the leaf position on which the mine is located (Fig. 5). We can see a significant difference between the shadow part and the illuminated part (Fig. 5b, c). The effect of different caterpillar generations on the efficiency of photochemical energy conversion in FS II $\left(\mathrm{F}_{\mathrm{m}}-\mathrm{F}_{\mathrm{St}}\right) / \mathrm{F}_{\mathrm{St}}$ has not been established (Fig. 5d). We see only the difference for the I and $\mathrm{V}$ generations in the position of the leaf in the crown.

\section{Discussion}

Under the conditions of caterpillar feeding, the time dependence of the chlorophyll fluorescence intensity had the characteristic form of a curve with one maximum, graphically reflecting the Kautsky effect. The shape of the Kautsky curves shows that background fluorescence under the influence of caterpillar feeding increased in the leaves of the shaded part of the crown compared to the illuminated part. This indicates an increase in the amount of chlorophyll not involved in photosynthetic energy transfer to reaction centers in damaged leaves.

Changes in the fluorescence intensity of chlorophyll FSI reflect oxidative processes in the reaction center of this photosystem. The absorbed energy of light quanta can be transferred in three ways: photochemical reactions, heat dissipation, and light emission as chlorophyll fluorescence. These processes compete with each other in such a way that the efficiency increasing of one results in the suppression of the other two. Therefore, the fluorescence intensity is sensitive to changes in the intensity of photochemical processes and thermal dissipation (Essemine et al., 2012; Rühle et al., 2018). An increase in temperature leads to the appearance of thermoinduction of chlorophyll at certain temperature values. The method for determining the parameters of the chlorophyll photosynthesis phenomenon in plant leaves (Kautsky curve) ensures the independence of measurement results from the temperature of the plant leaf, which leads to the appearance of thermoinduction of chlorophyll at certain temperature values and to an increase in accuracy (Starodub et al., 2015; Kalaji et al., 2016; Chen et al., 2018). Under normal conditions, the level of fluorescence is insignificant (1-2\% of the total absorbed light), which indicates the active use of absorbed light energy by cells. After lightening the leaves of plants adapted to the dark. First for a few seconds, there is a sharp increase in the intensity of chlorophyll fluorescence as a fast phase. Then within a few minutes, there is a gradual decrease through certain stages from the slow phase to the stationary level of $\mathrm{F}_{\mathrm{St}}$ (Martinazzo et al., 2012; Ruban, 2016).

The chart of changes in fluorescence from the beginning of illumination to reaching a stationary level consists of information about the state of the photosynthetic apparatus of the plant leaf. Changes $\mathrm{O}-\mathrm{I}-\mathrm{D}-\mathrm{P}$ are called the first wave or rapid induction of fluorescence. It occurs in 13 seconds, depending on the illumination intensity and other factors, and is observed both in living objects and isolated chloroplasts. Slower changes in $\mathrm{P}-\mathrm{S}-\mathrm{M}-\mathrm{T}$ are known as second-wave or slow induction of fluorescence. These changes occur over a period of several tens of seconds to several minutes, depending on the object and conditions of the experiment.

At the initial point in time, all channels of photosynthetic electron transfer are open, and the maximum energy of electron excitation goes to the photosynthetic process. During this period, chlorophyll fluorescence is minimal, and its intensity on the Kautsky curve is indicated by the letter $F$ with the " 0 " index, i.e. $\mathrm{F}_{0}$. Background fluorescence index $\left(\mathrm{F}_{0}\right)$ characterizes the inactive chlorophyll amount that does not have a functional connection with the reaction centers; that is, it acts as the initial level of induction of chlorophyll fluorescence. It depends on the loss of excitation energy during migration along with the pigment matrix. Thus, during active photosynthesis, when all the reaction centers are in an open working process, almost all the absorbed sunlight energy is used, and only a small amount of it (about $3 \%$ ) is converted into light energy in the form of background fluorescence $\left(\mathrm{F}_{0}\right)$. As a rule, the $\mathrm{F}_{0}$ index under normal conditions is low due to the active use of absorbed light energy by cells. The influence of $C$. ohridella feeding or other unfavourable conditions disrupts the state of photosynthetic membranes, and the reaction centers become inactive, stopping the flow of electrons. At the same time, the absorbed light energy can no longer be used in photosynthesis, and therefore chlorophyll fluorescence increases (Fig. 4).

$\mathrm{F}_{\mathrm{o}}-\mathrm{F}_{\mathrm{p}}$ transition is associated with a decrease in electron transport. It characterizes the thermal adaptation period of the leaf. If the adaptation period is short, the transition is steeper, but it is slower if the adaptation period is large. The $\mathrm{F}_{\mathrm{m}}$ parameter indicates the highest level of fluorescence, which is recorded on the induction curve as the maximum. The entire $\mathrm{F}_{\mathrm{o}}-\mathrm{F}_{\mathrm{m}}$ area is called the fast fluorescence phase. The slow phase of chlorophyll fluorescence induction represents all induction transitions after reaching the maximum value (peak) of $P$. The steady-state level of fluorescence $\left(\mathrm{F}_{\mathrm{St}}\right)$ is characterized by a dynamic equilibrium between the 
processes that cause an increase in fluorescence and the processes that lead to its decrease. As shown in Figure 4, there is a significant difference in the value of all key parameters of chlorophyll fluorescence induction. We have shown that with the caterpillar development (during all 5 of its generations), a gradual decrease in the values of all the main indicators $\left(\mathrm{F}_{\mathrm{o}}\right.$, $\mathrm{F}_{\mathrm{m}}, \mathrm{F}_{\mathrm{p}}$ and $\mathrm{F}_{\mathrm{St}}$ ) is observed, which affects the general physiological state of

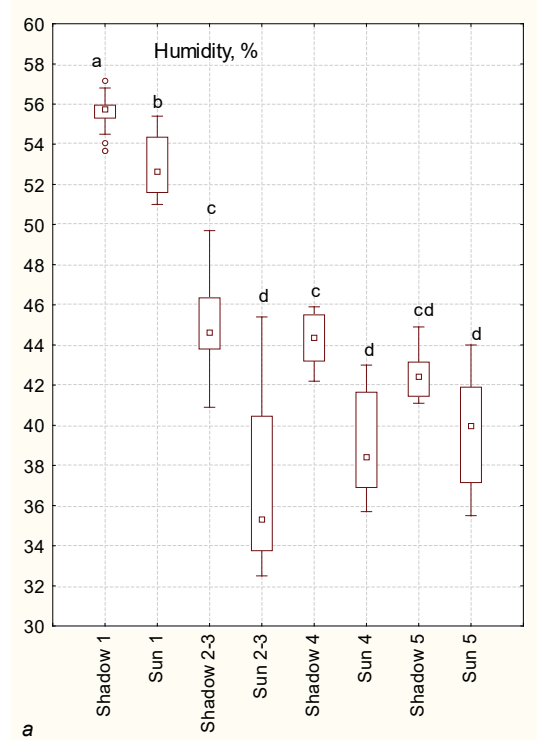

the leaf on which the $C$. ohridella mine is located. To characterize the photosynthetic apparatus under stress at the leaf level during the quick stage, the ratio of variable fluorescence $F_{v}$ to the maximum $F_{m}$ level is often used, which is considered an indicator of potential photosynthetic activity in the leaf (Starychenko et al., 2016; Tseng \& Chu, 2017; Scognamiglio et al., 2019).

Fig. 3. Influence of Cameraria ohridella caterpillars on the process of Aesculus hippocastanum photosynthesis depending on microclimatic factors: $a$-humidity $(\%) ; b$ - light intensity $(\mathrm{Lx}) ; c$ - temperature $\left({ }^{\circ} \mathrm{C}\right)$; on abscissa axis - measurement units of indicator, on ordinate axis - experimental variant; small square - median, upper and lower edges of rectangular square $-75 \%$ and $25 \%$ of quartile, vertical line - minimum and maximum values; $n=5$

Fluorescence variability $\left(\mathrm{F}_{\mathrm{v}}\right)$ is calculated as the difference between $\mathrm{F}_{\mathrm{m}}$ and $\mathrm{F}_{\mathrm{o}}$ values and it is a physiological indicator that reflects the influence of environmental and experimental factors on the plant (Alonso et al., 2017; Chitband et al., 2017; Huliaieva et al., 2018). However, this parameter has some limitations since it applies exclusively to primary photochemical processes in PS II and only during the first 100-500 ms. The effect of any adverse factor (in our case, this is possible damage caused by $C$. ohridella) reduces the attractive ability of the Calvin cycle, which stops the flow of electrons, and the reaction centers go into an inactive (closed) state. At the same time, photosynthesis can no longer use the absorbed light energy, and therefore chlorophyll fluorescence increases over the entire time range of recording its induction changes (Duarte et al., 2017; Rühle et al., 2018). The $\mathrm{F}_{\mathrm{V}} / \mathrm{F}_{\mathrm{m}}$ index depends on the efficiency of photochemical reactions of FS II. In dark-adapted plants, it reflects the potential quantum efficiency of FS II. This indicator is used as an indicator of photosynthetic productivity. Its optimal value for most plant species under conditions of saturating intensity of exciting light does not exceed 0.83 (Martinazzo et al., 2012).

It was found that an increase in the ambient temperature relative to the optimal one for this plant species leads to a decrease in the difference $F_{\mathrm{v}}=$ $\left(\mathrm{F}_{\mathrm{m}}-\mathrm{F}_{0}\right)$. The reason is a decrease in the electron transport chain activity or the light stage of photosynthesis. When the temperature rises to the level of destruction $\left(45 \ldots . .50^{\circ} \mathrm{C}\right)$, the level of $\mathrm{F}_{0}$ intensity increases markedly. In the breeding process, plant varieties resistant to high temperatures were quickly selected based on these indicators (Essemine et al., 2012; Martinazzo et al., 2012). Reducing the ambient temperature to the optimal level for this plant species also leads to a decrease in the value of $F_{v}=F_{m}-F_{0}$, which is caused by inhibition of the photochemical activity of FS II. The ratio $\left(\mathrm{F}_{\mathrm{m}}-\mathrm{F}_{0}\right) / \mathrm{F}_{\mathrm{v}}$ increases. Based on these characteristics, coldresistant plants can be selected. Water deficiency leads to a decrease in the $\mathrm{F}_{\mathrm{m}}-\mathrm{F}_{0}$ difference proportionally to the decrease in the water potential of the leaf. This indicator can be used to select drought-tolerant plant specimens (Chen et al., 2019). To estimate the fluorescence induction of chlorophyll-bearing tissues, the calculated parameter is used as the chlorophyll fluorescence variable $\left(\mathrm{F}_{\mathrm{v}}\right)$, which is expressed as the difference between the highest level of fluorescence and background fluorescence $F_{v}=F_{m}$ $\mathrm{F}_{0}$ giving information about the amplitude of changes in the Kautsky curve. In Figure 5b, we see a significant difference in the influence of the leaf position in the crown. The maximum efficiency of primary photosynthesis processes resulting from the physiological state of the plant is cha- racterized by the parameter $\mathrm{E}_{\mathrm{f}}=\mathrm{F}_{\mathrm{v}} / \mathrm{F}_{\mathrm{m}}$. The efficiency of photosynthesis, as well as the mentioned parameter, depends on the intensity of exposure to abiotic factors. The highest integrated indicator that characterizes the effective structure of the organization of the FS II pigment system is the $F_{v} / F_{m}$ coefficient. The $F_{m}$ parameter characterizes the highest level of chlorophyll fluorescence, which is recorded as the maximum on the induction curve. At this point, photosynthesis corresponds to the minimum level, and its value depends on the dynamic balance between the processes of fluorescence, photochemistry, and thermal dissipation. The obtained data demonstrate a decrease in the quantum efficiency of FS II (photosynthetic activity inhibition) in the leaves of the illuminated part of the crown, which indicates a destructive effect of $C$. ohridella caterpillar feeding on the photosynthetic apparatus of Ae. hippocastanum (Fig. 5c).

The efficiency of photochemical energy conversion in FS II is calculated by the formula $\mathrm{E}=\left(\mathrm{F}_{\mathrm{m}}-\mathrm{F}_{\mathrm{St}}\right) / \mathrm{F}_{\mathrm{St}}$, which characterizes the rate of linear electron transport and is an integrated indicator of the photosynthetic process. The ratio $\left(\mathrm{F}_{\mathrm{m}}-\mathrm{F}_{\mathrm{St}}\right) / \mathrm{F}_{\mathrm{St}}$ is called the plant viability index, where $\mathrm{F}_{\mathrm{m}}$ is the maximum fluorescence level, and $\mathrm{F}_{\mathrm{St}}$ is the steady level. Study of the feeding effect of $C$. ohridella caterpillars on the efficiency of the main enzyme of the Calvin cycle, which closely correlates with the fluorescence induction coefficient, which characterizes the efficiency of dark photosynthetic processes, demonstrated a significant decrease in its activity in the leaves of both the illuminated and shaded parts of the crown (Fig. 5d) for I and $\mathrm{V}$ generations.

One of the problems of comparing the parameters of the Kautsky curve for plants of both the same and different species is that the above time intervals can differ significantly for different plant species and also for different leaves of the same plant that have different ages or are adapted to different lighting conditions (for example, grow at the roots or on the crown, on old branches or on young shoots, well-illuminated or always darkened). As the stress factor increases, indicators of the fluorescence phenomenon, such as the "viability index", as well as the intensity of photosynthesis, usually decrease. The possibility of estimating the state of plants by changing the shape of the Kautsky curve has been confirmed experimentally (Elahifard et al., 2013; Duarte et al., 2017; Kyrychenko et al., 2019). The reason for the current limitations is because today there are no samples of the Kautsky curve for different plant species under normal conditions of their existence and for different ages. This means no "measure" by which it is possible to compare Kautsky curves under other conditions of plant existence. 

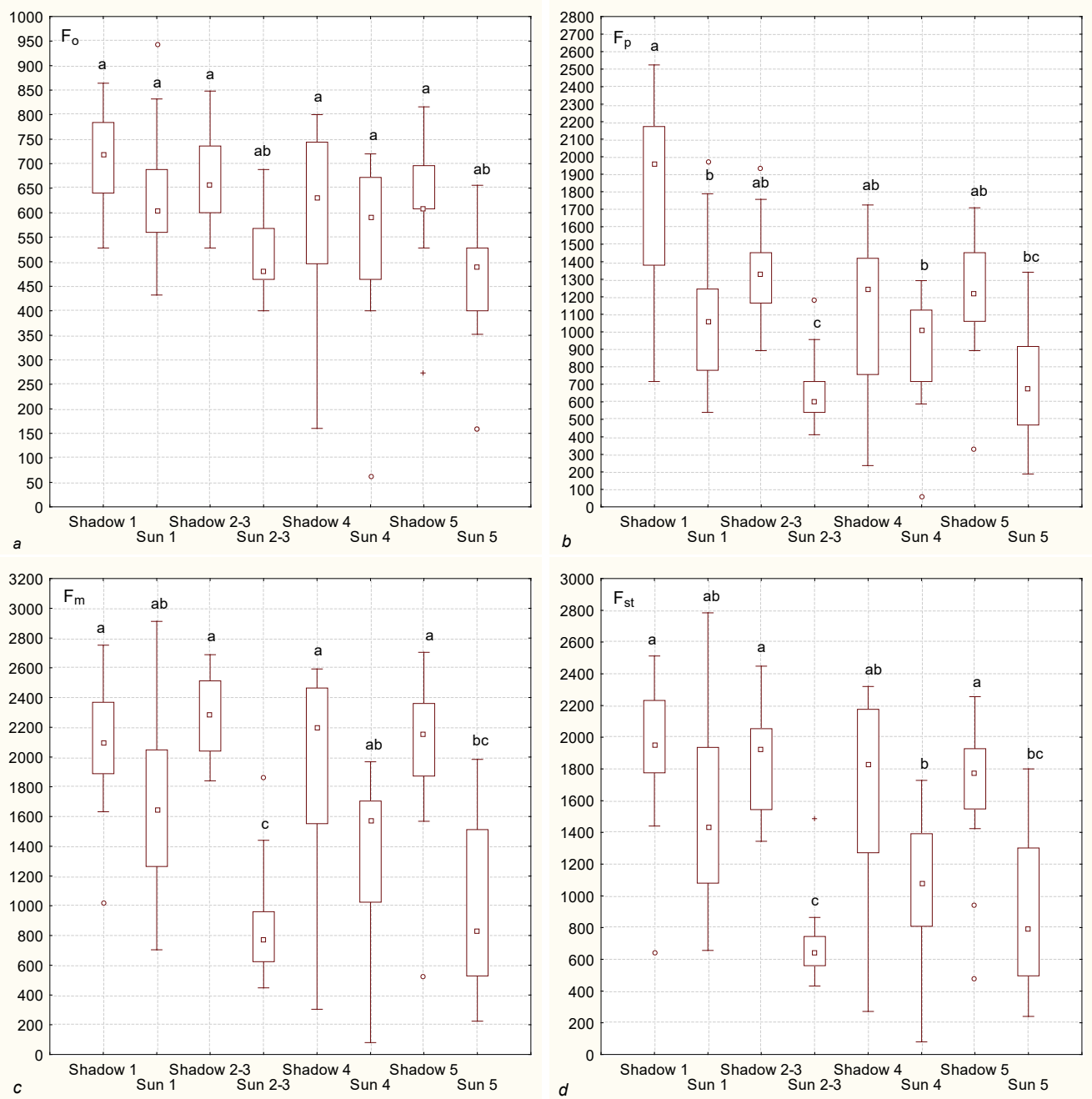

Fig. 4. Variability of indicators of the chlorophyll fluorescence induction curve (Kautsky curve) in Aesculus hippocastanum leaves damaged by Cameraria ohridella: $a-\mathrm{F}_{0}-$ the initial value of fluorescence induction after switching on irradiation; $b-\mathrm{F}_{\mathrm{p}}-$ the value of fluorescence induction "plateau"; $c-\mathrm{F}_{\mathrm{m}}$ - the maximum value of fluorescence induction; $d-\mathrm{F}_{\mathrm{St}}-$ the steady value of fluorescence induction after light adaptation of the leaf of the plant; on abscissa axis - measurement units of indicator, on ordinate axis - experimental variant; small square - median, upper and lower edges of rectangular square $-75 \%$ and $25 \%$ of quartile, vertical line - minimum and maximum values; $n=5$
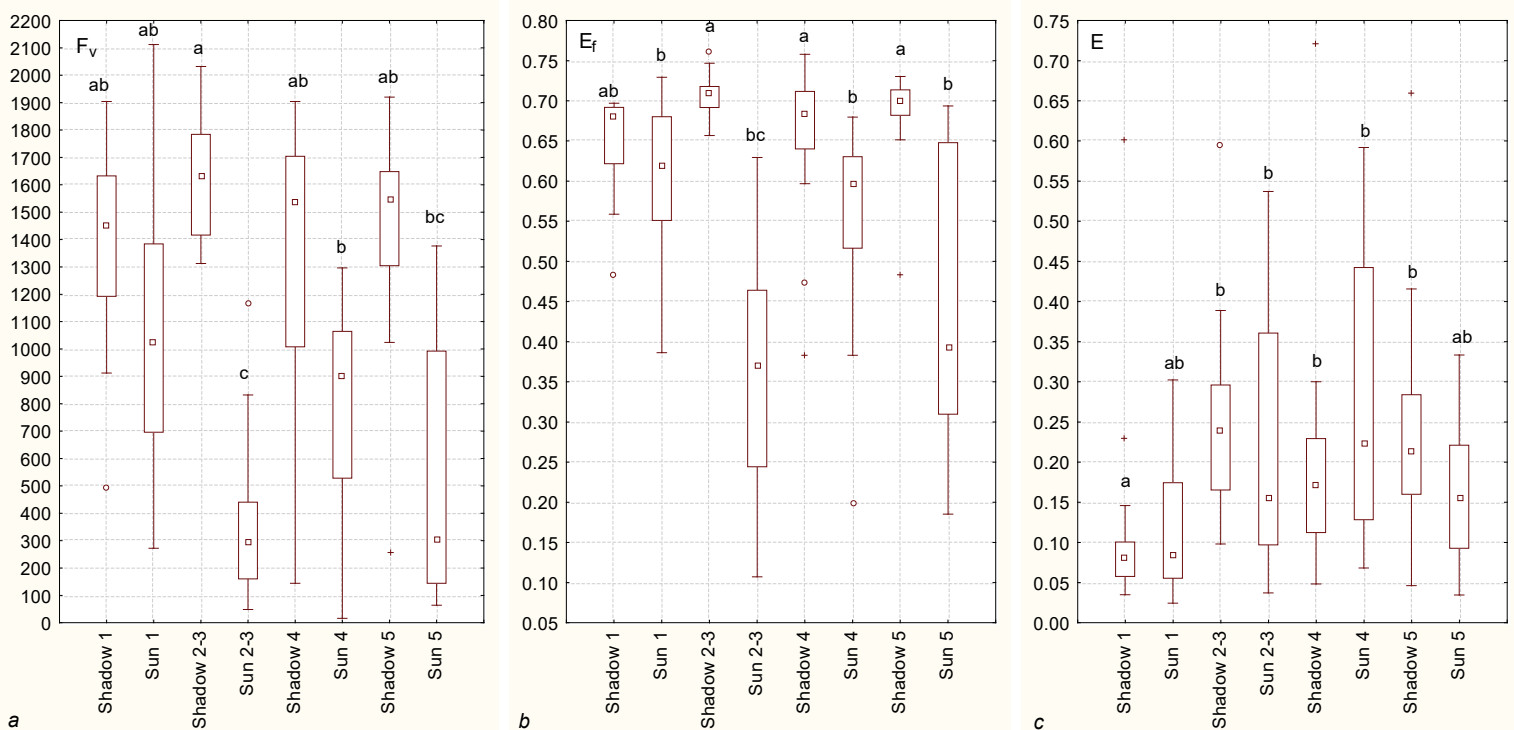

Fig. 5. Critical parameters of chlorophyll fluorescence induction in Aesculus hippocastanum leaves damaged by Cameraria ohridella: $a-\mathrm{F}_{\mathrm{V}}-$ variable chlorophyll fluorescence; $b-\mathrm{E}_{\mathrm{f}}-$ maximum efficiency of primary photosynthesis processes; $c-\mathrm{E}-$ efficiency of photochemical energy conversion in FS II; on abscissa axis - measurement units of indicator, on ordinate axis - experimental variant; small square - median, upper and lower edges of rectangular square $-75 \%$ and $25 \%$ of quartile, vertical line - minimum and maximum values; $n=5$ 


\section{Conclusion}

Feeding of $C$. ohridella caterpillars causes a decrease in the photosynthetic apparatus activity of Ae. hippocastanum regardless of the spatial arrangement of leaves in the tree's crown. In Ae. hippocastanum leaves under the influence of $C$. ohridella feeding, the amount of chlorophyll not involved in photosynthetic energy transfer to reaction centers increases. Conversely, during the development of only one generation of $C$. ohridella a constant decrease in the quantum efficiency of FS II (inhibition of photosynthetic activity) was observed. Already at the beginning of the development of the mine (the first-age $C$. ohridella caterpillars) on the leaves in the illuminated and shaded part of the crown, a significant decrease in activity and an increase in the plateau coefficient were observed, which in turn indicates inhibition of photophysical and photochemical processes of photosynthesis and a reduction in the pool of electron acceptors in the electron transport chain. Such pathological changes were caused by a decrease in the content of active chlorophyll (a component of pigment-protein complexes FS II) and its destruction. The values of the key parameters of chlorophyll fluorescence induction indicate a significant inhibition of photosynthesis processes and a violation of the coherence of Calvin cycle reactions. The consequence of the photosynthetic apparatus damage in plants is a decrease in the content of photosynthetic pigments since these metabolic transformations are determined by local changes in the structure and functions of chloroplasts.

\section{References}

Akimov, I. A., Zerova, M. D., Gershenson, Z. S., Narol'skij, I. V., Kohanec, A. M., \& Sviridov, S. V. (2003). Pervoe soobshhenie o pojavlenii v Ukraine kashtanovoj mininjushhej moli Cameraria ohridella Desch. \& Dem. (Lepidoptera, Gracillariidae) na konskom kashtane obyknovennom [The first report on the appearance in Ukraine of the chestnut mining moth Cameraria ohridella Desch. \& Dem. (Lepidoptera, Gracillariidae) on common horse chestnuts]. Vesnik of Zoology, 37(1), 3-12 (in Russian).

Alonso, L., Van Wittenberghe, S., Amorós-López, J., Vila-Francés, J., Gómez-Chova, L., \& Moreno, J. (2017). Diumal cycle relationships between passive fluorescence, PRI and NPQ of vegetation in a controlled stress experiment. Remote Sensing, 9(8), 770.

Brygadyrenko, V. V. (2015). Influence of tree crown density and density of the herbaceous layer on the structure of litter macrofauna of deciduous forests of Ukraine's steppe zone. Visnyk of Dnipropetrovsk University, Biology, Ecology, 23(2), 134-148.

Brygadyrenko, V. V. (2016). Influence of litter thickness on the structure of litter macrofauna of deciduous forests of Ukraine's steppe zone. Visnyk of Dnipropetrovsk University, Biology, Ecology, 24(1), 240-248.

Brygadyrenko, V. V., \& Nazimov, S. S. (2015). Trophic relations of Opatrum sabulosum (Coleoptera, Tenebrionidae) with leaves of cultivated and uncultivated species of herbaceous plants under laboratory conditions. Zookeys, 481, 57-68.

Chen, J., Burke, J. J., \& Xin, Z. (2018). Chlorophyll fluorescence analysis revealed essential roles of FtsH11 protease in regulation of the adaptive responses of photosynthetic systems to high temperature. BMC Plant Biology, 18(1), 11.

Chen, X., Mo, X., Hu, S., \& Liu, S. (2019). Relationship between fluorescence yield and photochemical yield under water stress and intermediate light conditions. Journal of Experimental Botany, 70(1), 301-313.

Chitband, A. A., Ghorbani, R., Rashed Mohassel, M. H., \& Nabizade, M. (2017). The effect of sugar beet broadleaf herbicides on fluorescence induction curves in Amaranthus retroflexus L. and Portulaca oleracea L. Notulae Scientia Biologicae, $9(3), 433-442$.

da Silva, J. M., Figueiredo, A., Cunha, J., Eiras-Dias, J. E., Silva, S., Vanneschi, L., \& Mariano, P. (2020). Using rapid chlorophyll fluorescence transients to classify Vitis genotypes. Plants, 9, 174.

Duarte, B., Pedro, S., Marques, J. C., Adão, H., \& Caçador, I. (2017). Zostera noltii development probing using chlorophyll $a$ transient analysis (JIP-test) under field conditions: Integrating physiological insights into a photochemical stress index. Ecological Indicators, 76, 219-229.

Elahifard, E., Ghanbari, A., Mohassel, M. H. R., Zand, E., Kakhki, M. A., \& Abbaspoor, M. (2013). Measuring chlorophyll fluorescence parameters for rapid detection of ametryn resistant junglerice [Echinochloa colona (L.) Link.]. Plant Knowledge Journal, 2(2), 76-82.

Essemine, J., Govindachary, S., Joly, D., Ammar, S., Bouzid, S., \& Carpentiera, R. (2012). Effect of moderate and high light on photosystem II function in Arabidopsis thaliana depleted in digalactosyl-diacylglycerol. Biochimica et Biophysica Acta-Bioenergetics, 1817(8), 1367-1373.
Faly, L. I., Kolombar, T. M., Prokopenko, E. V., Pakhomov, O. Y., \& Brygadyrenko, V. V. (2017). Structure of litter macrofauna communities in poplar plantations in an urban ecosystem in Ukraine. Biosystems Diversity, 25(1), 29-38.

Gorbunov, M. Y., \& Falkowski, P. G. (2021). Using chlorophyll fluorescence kinetics to determine photosynthesis in aquatic ecosystems. Limnology and Oceanography, 66(1), 1-13.

Govindjee, G. (2004). Chlorophyll $a$ fluorescence: A bit of basics and history. In: Papageorgiou, G. C., \& Govindjee, G. (Eds.). Chlorophyll $a$ fluorescence: A signature of photosynthesis. Springer, Dordrecht. Pp. 1-41.

Holoborodko, K. K., Marenkov, O. M., Gorban, V. A., \& Voronkova, Y. S. (2016). The problem of assessing the viability of invasive species in the conditions of the steppe zone of Ukraine. Visnyk of Dnipropetrovsk University, Biology, Ecology, 24(2), 466-472.

Huang, Y., Thomson, S. J., Molin, W. T., Reddy, K. N., \& Yao, H. (2012). Early detection of soybean plant injury from glyphosate by measuring chlorophyll reflectance and fluorescence. Journal of Agricultural Science, 4(5), 117-124.

Huliaieva, H., Tokovenko, I., Maksin, V., Kaplunenko, V., \& Kalinichenko, A. (2018). Effect of nanoaquacitrates on physiological parameters of Fodder gale$g a$ infected with phytoplasma. Ecological Chemistry and Engineering S, 25(1), $153-168$.

Inghilesi, A. F., Mazza, G., Cervo, R., Gherardi, F., Sposimo, P., Tricarico, E., \& Zapparoli, M. (2013). Alien insects in Italy: Comparing patterns from the regional to European level. Joumal of Insect Science, 13, 1-13.

Kalaji, H. M., Jajoo, A., Oukarroum, A., Brestic, M., Zivcak, M., Samborska, I. A., Cetner, M. D., Łukasik, I., Goltsev, V., \& Ladle, R. J. (2016). Chlorophyll $a$ fluorescence as a tool to monitor physiological status of plants under abiotic stress conditions. Acta Physiologiae Plantarum, 38(102), 1-11.

Kalaji, H. M., Schansker, G., Brestic, M., Bussotti, F., Calatayud, A., Ferroni, L., Goltsev, V., Guidi, L., Jajoo, A., Li, P., Losciale, P., Mishra, V. K., Misra, A. N., Nebauer, S. G., Pancaldi, S., Penella, C., Pollastrini, M., Suresh, K., Tambussi, E., Yanniccari, M., Zivcak, M., Cetner, M. D., Samborska, I. A., Stirbet, A., Olsovska, K, Kunderlikova, K., Shelonzek, H., Rusinowski, S., \& Bąba, W. (2017). Frequently asked questions about chlorophyll fluorescence, the sequel. Photosynthesis Research, 132(1), 13-66.

Kargar, M., Ghorbani, R., Rashed Mohassel, M. H., \& Rastgoo, M. (2019). Chlorophyl fluorescence - a tool for quick identification of Accase and ALS inhibitor herbicides performance. Planta Daninha, 37, e019166813.

Kautsky, H., \& Hirsch, A. (1931). Neue Versuche zur Kohlensäureassimilation. Naturwissenschaften, 19,964.

Kirichenko, N., Augustin, S., \& Kenis, M. (2019). Invasive leafminers on woody plants: A global review of pathways, impact, and management. Journal of Pest Science, 92(9), 1-14.

Kyrychenko, A. M., Hrynchuk, K. V., \& Antipov, I. O. (2019). Vplyv virusiv rodyny Potyviridae na funktsional'nyy stan i aktyvnist' fotosyntetychnoho aparatu bobovykh [The effect of viruses of the family Potyviridae on the functional state and activity of the photosynthetic apparatus of legumes]. Agroecological Journal, 2, 62-71 (in Ukrainian).

Lopez-Vaamonde, C., Agassiz, D., Augustin, S., De Prins, J., De Prins, W., Gomboc, S., Ivinskis, P., Karsholt, O., Koutroumpas, A., Kouttoumpa, F., Laštůvka, Z., Marabuto, E., Olivella, E., Przybylowicz, L., Roques, A., Ryrholm, N., Šefrová, H., Šma, P., Sims, P., Sinev, S., Skulev, B., Tomov, R., Zilli, A., \& Lees, D. (2010). Chapter 11. Lepidoptera. In: Roques, A. (Ed.). Alien terrestrial arthropods of Europe. BioRisk, 4(2), 603-668.

Martinazzo, E. G., Ramm, A., \& Bacarin, M. A. (2012). The chlorophyll $a$ fluorescence as an indicator of the temperature stress in the leaves of Prunus persica. Brazilian Journal of Plant Physiology, 24(4), 237-246.

Matorin, D. N., Timofeeva, N. P., Sindalovskaya, M. L., Shidlovskaya, N. A., Todorenkoa, D. A., \& Alekseev, A. A. (2019). Chlorophyll fluorescence of summer phytoplankton in reservoirs of the Zvenigorod Biological Station of Moscow State University. Biophysics, 64(6), 858-865.

Pérez-Bueno, M. L., Pineda, M., \& Barón, M. (2019). Phenotyping plant responses to biotic stress by chlorophyll fluorescence imaging. Frontiers Plant Science, 10, 1135 .

Ruban, A. V. (2016). Nonphotochemical chlorophyll fluorescence quenching: Mechanism and effectiveness in protecting plants from photodamage. Plant Physiology, 170, 1903-1916.

Rühle, T., Reiter, B., \& Leister, D. (2018). Chlorophyll fluorescence video imaging: A versatile tool for identifying factors related to photosynthesis. Frontiers Plant Science, 9, 55.

Scognamiglio, V., Antonacci, A., Arduini, F., Moscone, D., Campos, V. R. E., Fraceto, L. F., \& Palleschi, G. (2019). An eco-designed paper-based algal biosensor for nanoformulated herbicide optical detection. Journal of Hazardous Materials, 373, 483-492.

Shupranova, L. V., Holoborodko, K. K., Seliutina, O. V., \& Pakhomov, O. Y. (2019). The influence of Cameraria ohridella (Lepidoptera, Gracillariidae) on the activity of the enzymatic antioxidant system of protection of the assimilating organs of Aesculus hippocastanum in an urbogenic environment. Biosystems Diversity, 27(3), 238-243. 
Starodub, N. F., Guidotti, M., Shavanova, K. E., Taran, M. V., \& Son'ko, R. V. (2015). Ways for the control of the total toxicity of environmental objects and their instrumental providing. Biosensors and Bioelectronics, 6, 180.

Starychenko, V., Golyk, L., \& Patyka, M. (2016). Fluorescence of chlorophyll pigment in leaves of soft winter wheat annual at different stages of organogenesis. Bulletin of Agricultural Science, 9, 25-29.
Tseng, Y.-C., \& Chu, S.-W. (2017). High spatio-temporal-resolution detection of chlorophyll fuorescence dynamics from a single chloroplast with confocal imaging fuorometer. Plant Methods, 13, 43.

Voronkova, Y. S., Marenkov, O. M., \& Holoborodko, K. K. (2018). Liver antioxidant system of the Prussian carp and pumpkinseed as response to the environmental change. Ukrainian Journal of Ecology, 1(8), 749-754. 